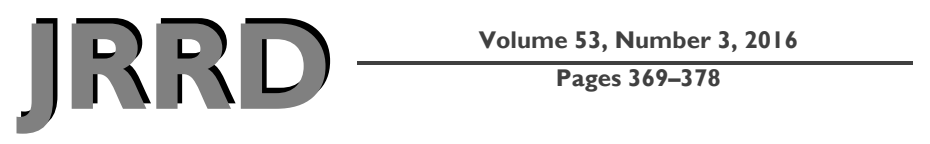

\title{
Impact testing of the residual limb: System response to changes in prosthetic stiffness
}

\author{
Erin Boutwell, PhD; ${ }^{1-3^{*}}$ Rebecca Stine, MS; ;,3 $^{3}$ teven Gard, PhD ${ }^{1-3}$ \\ ${ }^{1}$ Northwestern University Prosthetics-Orthotics Center and Department of Physical Medicine and Rehabilitation, \\ Feinberg School of Medicine, Northwestern University, Chicago, IL; ${ }^{2}$ Department of Biomedical Engineering, McCor- \\ mick School of Engineering and Applied Science, Northwestern University, Evanston, IL; ${ }^{3}$ Jesse Brown Department of \\ Veterans Affairs Medical Center, Chicago, IL
}

\begin{abstract}
Currently, it is unknown whether changing prosthetic limb stiffness affects total limb stiffness and/or influences the shock absorption of an individual with transtibial amputation. The hypotheses tested within this study are that a decrease in longitudinal prosthetic stiffness will produce (1) reduced total limb stiffness and (2) reduced magnitude of peak impact forces and increased time delay to peak force. Fourteen subjects with a transtibial amputation participated in this study. Prosthetic stiffness was modified by means of a shock-absorbing pylon that provides reduced longitudinal stiffness through compression of a helical spring within the pylon. A sudden loading evaluation device was built to examine changes in limb loading mechanics during a sudden impact event. No significant change was found in the peak force magnitude or timing of the peak force between prosthetic limb stiffness conditions. Total limb stiffness estimates ranged from 14.9 to $17.9 \mathrm{kN} / \mathrm{m}$ but were not significantly different between conditions. Thus, the prosthetic-side total limb stiffness was unaffected by changes in prosthetic limb stiffness. The insensitivity of the total limb stiffness to prosthetic stiffness may be explained by the mechanical characteristics (i.e., stiffness and damping) of the anatomical tissue within the residual limb.
\end{abstract}

Key words: artificial limbs, elasticity, impact loading, lowerlimb, mechanical stress, prosthesis, residual limb, shock, stiffness, transmission, transtibial amputee.

\section{INTRODUCTION}

Compliant (i.e., reduced-stiffness) components are often prescribed for use in lower-limb prostheses to improve comfort and reduce peak forces at the residual limb interface during walking, running, jumping, and other activities. To date, however, clinicians and researchers lack a good understanding of how these components function within the residual limb-prosthesis system. Compliant components are often referred to as "shock absorbing" since they are intended to influence the force transmission of the prosthetic limb by reducing the overall limb stiffness. In nondisabled individuals, limb stiffness is believed to affect many functional gait characteristics: the rate of loading, energy storage (shock

\footnotetext{
Abbreviations: ANOVA = analysis of variance, GRF = ground reaction force, JBVAMC = Jesse Brown Department of Veterans Affairs Medical Center, MTP = metatarsophalangeal, SAP = shock-absorbing pylon, SLED = sudden loading evaluation device.

*Address all correspondence to Erin Boutwell, PhD; Northwestern University Prosthetics-Orthotics Center, 680 North Lake Shore Dr, Suite 1100, Chicago, IL 60611; 312503-5700; fax: 312-503-5760.

Email: e-boutwell@u.northwestern.edu http://dx.doi.org/10.1682/JRRD.2014.10.0234
} 
absorption), and cadence [1]. Indeed, the influence of leg stiffness on the body has been likened to a "virtual passive controller" that diminishes vibration transmission from the impact of the foot with the ground [2]. It follows that stiffness properties of the prosthetic limb may also serve many of these same functions. However, contrary to expectations, previous gait studies have not demonstrated that "shock absorbing" prosthetic components have an appreciable effect on ground reaction force (GRF) profiles [3-11].

The mechanical characteristics of prosthetic components-typically described by their mass, damping, and stiffness values-have been assessed by both manufacturers and independent researchers to better understand their loading properties [12-14]. However, when a prosthetic component is integrated with a human limb, its behavior may be influenced by anatomical features of the system. The human body consists of many different types of tissues, achieves a vast array of possible limb configurations, and is characterized by dynamic modulation of the neuromuscular system. Because of these complex characteristics, it has been suggested that testing prosthetic components in vivo, with the human acting as part of the test system, represents a preferable environment for the assessment of prosthetic function [15].

It is also essential to evaluate the ability of reduced prosthetic stiffness to exert a meaningful influence on the limb system in a systematic, independent manner. Interpretation of results from previous studies has often been hindered by confounding variables, as changes in the stiffness of a particular prosthetic component are often accompanied by changes in other notable considerations such as mass, material, or alignment [16]. Additionally, the purpose of these compliant prosthetic components is to protect the residual limb's musculoskeletal system from the forces transmitted along the limb during walking. Thus, it makes sense to design a testing protocol to evaluate the residual limb-prosthesis combination in a configuration in which (1) the forces are directed longitudinally (the orientation of the GRF vector during the early stance phase of gait [17-18]) and (2) the stiffness element is aligned longitudinal to the limb.

Neuromuscular adaptation by the prosthesis user to modifications in prosthetic stiffness has been suggested as a possible explanation of gait results-specifically, unchanged GRFs - in previous prosthetic component studies $[10,19]$. If present, this adaptation may occur in the form of altered joint configurations or muscular cocontraction, both of which have been identified as non- disabled limb responses to changes in surface stiffness [20]. Complicated tasks such as gait enable substantial dynamic neuromodulation, but inhibiting the neuromuscular system experimentally is often impractical. A simple, investigator-controlled event—such as a short, fast fall-may reduce the dynamic response of the motor control system and permit an evaluation of the effect of reduced-stiffness components on force transmission independent of active adaptation strategies by delivering a consistent lower-limb impact.

The purpose of this study was to determine whether altered prosthetic stiffness produces a substantial change in the total limb stiffness when incorporated within the passive structures of the residual limb. These changes in total limb stiffness would also be reflected in modifications to the impact force loading profile during a controlled impact event, which was designed to build upon knowledge gained from previous mechanical testing and gait analyses. The hypotheses tested within this study are that (1) a decrease in longitudinal prosthetic stiffness will reduce total limb stiffness, and (2) a decrease in longitudinal prosthetic stiffness will reduce the magnitudes of peak impact forces and increase the time delay to peak force. An impact testing apparatus designed in-house was utilized to generate an impact beneath the prosthetic limb in which the forces were directed longitudinally along the limb. Additionally, a relatively broad range of prosthetic stiffness levels was tested to determine which levels of stiffness influence total limb stiffness and impact forces.

\section{METHODS}

\section{Subject Recruitment}

Subjects were recruited from a convenience sample of individuals associated with the Northwestern University Prosthetics-Orthotics Center and the Jesse Brown Department of Veterans Affairs Medical Center (JBVAMC) according to the following inclusion criteria: an age of 18 to $80 \mathrm{yr}$, a transtibial amputation, and more than 6 mo of experience with a definitive prosthesis. Exclusion criteria were as follows: skin problems on the residual limb, painful neuromata or other pressure sensitive tissue, or a body mass exceeding the specified limit of the prosthetic components $(>125 \mathrm{~kg})$. All subjects provided written informed consent prior to participation in this study, and experimental procedures were approved by the Northwestern University Institutional Review Board. 


\section{Experimental Prosthesis}

Longitudinal prosthetic stiffness was modified by means of a commercially available shock-absorbing pylon (SAP). In addition to the SAP, a standardized shoe and foot were provided to all subjects to maintain consistency within the distal components of the prosthesis. The foot (Seattle Lightfoot, Trulife; Dublin, Ireland) and flat canvas shoe (Target Corp; Minneapolis, Minnesota) were selected because of their relatively minimal deformation in the longitudinal direction, permitting the compression of the SAP to be predominant within the prosthesis. Subjects wore their own socket and suspension system for the duration of the experiment.

The selected model of SAP (Endolite TT Pro; Miamisburg, Ohio) provides reduced longitudinal stiffness through compression of a helical spring within the pylon. Springs with different stiffness values are commercially available with this pylon; the manufacturer provides stiffness recommendations for a user based upon body weight and activity level. These recommendations were used to assign each study subject to an experimental spring set (A or B). Both spring sets were comprised of four stiffness conditions based around the manufacturer recommended stiffness level (designated the "NORMAL" condition). Lower stiffness experimental conditions were then created by incorporating springs having 50 percent (the "SOFT" condition) and 75 percent (the "MEDIUM" condition) of the normal stiffness. These additional springs were acquired from mechanical supply companies or were custom ordered as necessary, and mechanical testing was performed to confirm the spring stiffness values (Table 1). Finally, a "RIGID" condition was created by replacing the springs with a steel cylinder that prevented compression of the pylon. It should also be noted that when operating normally the TT Pro pylon allows transverse plane rotation; this feature was blocked during the experiment to constrain motion to a single degree of freedom. The order of the prosthetic stiffness conditions was randomized using a random integer gen- erator, and the subject was blinded as to the prosthetic stiffness condition.

A Certified Prosthetist assembled the experimental prosthesis and performed an initial benchtop alignment. The prosthetist then tightened the anterior set screw at the pylon/foot interface until the foot was in at least $5^{\circ}$ of dorsiflexion when the subject was seated on the experimental device. This alignment ensured that the plantar surface of the rearfoot (i.e., the portion of the foot beneath the pylon) would make initial contact with the force platform during impact testing. This alignment was maintained throughout all impact testing trials.

\section{Test Apparatus}

A sudden loading evaluation device (SLED) was designed and built to examine changes in limb loading mechanics during a sudden impact event. The design specifications, reliability, and validation are described in greater detail elsewhere [21]. The SLED was modified from a commercial home gym apparatus composed of an inclined track with a rolling platform and terminating with a force platform (AMTI; Watertown, Massachusetts) at its base (Figure 1(a)).

\section{Testing Procedure}

All impact testing was conducted in a motion analysis laboratory equipped with 12 cameras (Motion Analysis Corporation; Santa Rosa, California). Reflective markers were placed on the subjects' legs and prosthesis to track the motion of the lower body during the impact experiment (Figure 1(b)). Bilateral markers were placed on the greater trochanters of the femurs and the anterior and lateral aspects of the thigh segments. Markers were placed on the intact limb in the following locations: the medial and lateral femoral epicondyles, the anterior tibia, the medial and lateral malleoli, the calcaneus, and the dorsal aspect of the foot over the 3rd metatarsophalangeal (MTP) joint. Markers specific to the prosthetic limb

Table 1.

Experimental stiffness conditions. Subjects were assigned to a spring set based on body mass and activity level according to manufacturer instructions.

\begin{tabular}{lccccrc}
\hline \multirow{2}{*}{ Spring Condition } & \multicolumn{2}{c}{ Spring Set A } & & \multicolumn{2}{c}{ Spring Set B } \\
\cline { 2 - 3 } \cline { 5 - 6 } & Stiffness $\mathbf{( k N / m )}$ & \% of Recommended & & Stiffness (kN/m) & \% of Recommended \\
\hline SOFT & 68.2 & 61.0 & 79.9 & 85.6 & 55.7 \\
MEDIUM & 89.3 & 100.0 & & 111.8 & 72.7 \\
NORMAL & 111.8 & $3,181.2$ & 153.8 & 100.0 \\
RIGID & $3,556.9$ & & $3,556.9$ & $2,312.7$ \\
\hline \hline
\end{tabular}




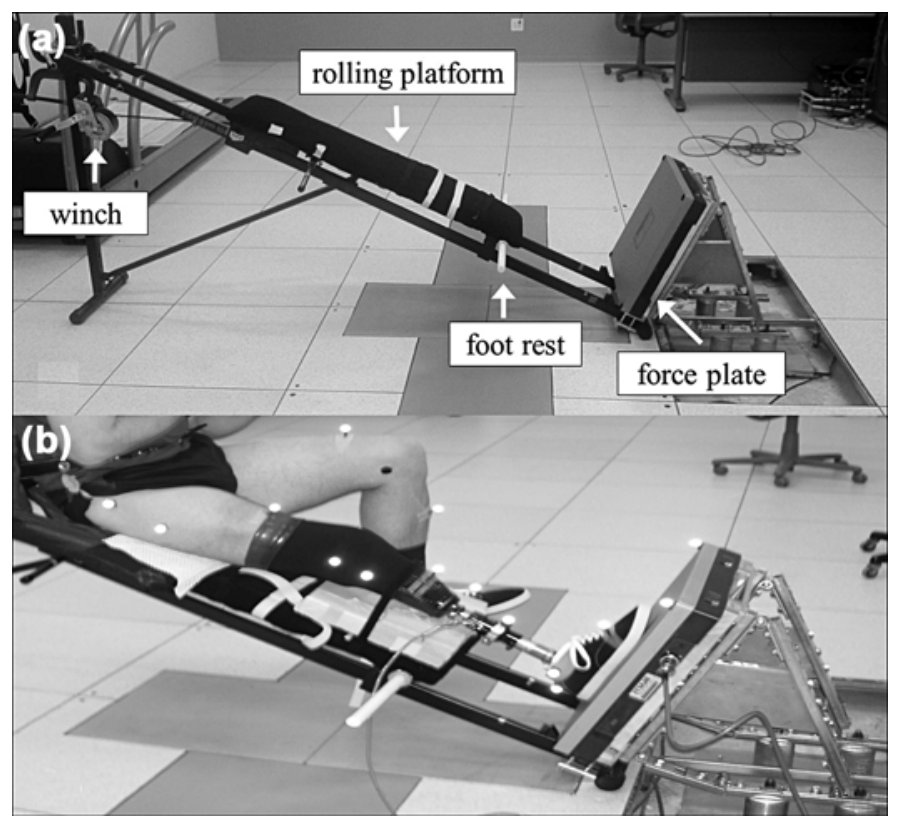

Figure 1.

(a) The sudden loading evaluation device (SLED) apparatus. The SLED consists of a modified gym apparatus in which the original base plate was replaced by a force plate. The force plate was secured to mounting brackets bolted directly to the concrete laboratory floor. A winch system was installed to permit easy raising and lowering of the rolling platform. A foot rest was also added to provide a resting place for the nontested limb. (b) Subject positioned on the SLED. Prosthetic limb is extended and in contact with the force plate. Reflective markers track limb position and are used to calculate impact velocity.

included the medial and lateral points of the estimated knee axis of rotation over the socket, the anterior and lateral aspects of the socket, the anterior aspect of the pylon distal to the spring, the lateral and medial approximation of the anatomical ankle axis of rotation on the prosthetic foot, and the prosthetic-side shoe at the estimated calcaneus and MTP joint locations. Markers were also placed on the force platform, the SLED frame, the seat back, and the rolling platform.

After the experimental prosthesis was fit and the markers were attached, subjects were seated on the SLED with their prosthetic limb extended toward the force plate (Figure 1(b)). An extended limb position was preferred because a neutral limb joint configuration $\left(0^{\circ}\right.$ knee flexion, $90^{\circ}$ angle between the shank and the "ground") lessens the involvement of the lower-limb joints in altering total limb stiffness [22]. When seated, the base of the subject's socket aligned approximately with the bottom edge of the rolling platform. A waist restraint belt was fastened around the subject and seat back to maintain gross body position. Subjects were instructed to maintain an extended limb posture throughout the course of the experiment, with knee flexion inhibited (but not disallowed, for safety and comfort) by straps placed loosely over the distal thigh segment; an additional strap was placed over the proximal end of the tibia if possible based on leg length and socket configuration. The intact limb was placed on a footrest attached to the lower portion of the rolling platform. Subjects received verbal instructions to remain as relaxed as possible throughout the experiment and not to participate actively during the impact event.

A winch system moved the subject further or closer to the force platform along the inclined track. The drop height of $5 \mathrm{~cm}$ was determined based on two factors. First, a $5 \mathrm{~cm}$ drop should produce an impact velocity of approximately $0.644 \mathrm{~m} / \mathrm{s}$ according to Equation 1, which is within the range of vertical heel velocities achieved during walking at various speeds [23].

$$
d=\frac{v^{2}}{2 g \sin \theta} \text {, }
$$

where $d$ is drop height, $v$ is impact velocity, $g$ is acceleration due to gravity, and $\theta$ is the inclination angle of the track.

Impact velocity was constrained within the range of normal walking speeds to ensure safe loading levels during the impact event. Secondly, a $5 \mathrm{~cm}$ drop should ensure a freefall phase of less than $200 \mathrm{~ms}$, the threshold below which the neuromuscular system cannot generate a preimpact plan in response to the sudden drop [24-25].

Once the subject was in the starting position, the investigator notified the subject that the trial was about to begin. The investigator then activated the quick-release lever on the winch, releasing the rolling platform into a gravity-propelled fall that terminated when the prosthetic limb contacted the force platform. Ten warm-up trials of heights less than or equal to $5 \mathrm{~cm}$ were performed to acclimate the subject to the sensation of the impact event and minimize the possibility of startle effects; these warm-up trials were performed using the first randomly ordered experimental stiffness condition. Following this warm-up period, five trials were collected for each of the four stiffness conditions. 


\section{Data Processing}

Analog data from the force platform were collected using Cortex software (Motion Analysis Corporation) and then exported into an ASCII file format. These data were then imported into MATLAB (MathWorks; Natick, Massachusetts), where the force in the $z$ direction (orthogonal to the surface of the force platform) was passed through a 4th order, zero-phase Butterworth filter having a cutoff frequency of $90 \mathrm{~Hz}$. The start of the impact event was identified by selecting the frame at which the force magnitude first rose above a threshold force of $20 \mathrm{~N}$, and this frame was labeled as $t=0$. Subsequently, the time to and magnitude of the peak impact force were identified. Marker position data were captured and postprocessed in Cortex, exported into an ASCII file format, and imported into MATLAB. The marker data were then passed through a 4th order, zero-phase Butterworth filter having a cutoff frequency of $11.25 \mathrm{~Hz}$. The sampling rates of the marker and force data differed ( $240 \mathrm{~Hz}$ vs $1,920 \mathrm{~Hz}$ ), so the marker data were interpolated in MATLAB to generate datasets of equal length.

Velocity of the subject at impact and knee flexion during the impact event were calculated to determine consistency of the impact event. Impact velocity was calculated through numerical differentiation of the position of the ankle marker prior to force onset. Knee flexion was calculated as the difference between force onset and peak force in the two-dimensional $(y, z)$ angle between the thigh (defined as the trochanter marker to the knee marker) and the shank (defined as the knee marker to the ankle marker). The total limb stiffness was calculated using displacement estimates obtained through double integration of the force record [26]. The initial length of the limb was set as zero, and the initial velocity corresponded to the previously calculated impact velocity.

\section{Statistical Analysis}

Based on the randomized crossover design, a repeated measures analysis of variance (ANOVA) was selected as the appropriate statistical procedure. Following data collection, statistically significant differences between prosthetic stiffness conditions were analyzed using a nonparametric ANOVA for ranks (i.e., Friedman test). A post hoc Bonferroni correction was performed to account for the multiple comparisons. All statistical analyses were performed using IBM SPSS Statistics 22 (IBM Corp; Armonk, New York).

\section{RESULTS}

Fourteen subjects with a transtibial amputation participated in this study (Table 2). The mean age of the

Table 2.

Subject characteristics.

\begin{tabular}{|c|c|c|c|c|c|}
\hline Subject & Sex & Age (yr) & Mass (kg) & Amputation Etiology & Yr Since Amputation \\
\hline 1 & $\mathrm{M}$ & 70 & 82 & Trauma & 37 \\
\hline 2 & M & 24 & 75.5 & Trauma & 5 \\
\hline 4 & M & 29 & 78.5 & Trauma & 4 \\
\hline 5 & M & 31 & 78.5 & Cancer & 11 \\
\hline 8 & M & 73 & 74 & Trauma & 20 \\
\hline 9 & $\mathrm{~F}$ & 64 & 99.25 & Trauma & 12 \\
\hline 10 & $\mathrm{~F}$ & 37 & 52.5 & Trauma & 10 \\
\hline 11 & M & 55 & 119 & Vascular & 9 \\
\hline Mean \pm SD & - & $48.6 \pm 16.3$ & $81.2 \pm 15.9$ & - & $16.1 \pm 13.6$ \\
\hline
\end{tabular}


subjects was $48.6 \pm 16.3 \mathrm{yr}$, and mean mass was $81.2 \pm$ $15.9 \mathrm{~kg}$. The average peak force achieved during the impact event ranged between 97.5 and 100.3 percent of body weight, and the distributions differed significantly ( $p=0.04$ ); however, no statistically significant difference was found in the pairwise comparisons after the $p$-value was corrected for multiple comparisons (Table 3).

Typical force profiles for the impact events are shown for a single subject (Figure 2). No significant change was found in the timing of the peak force between conditions $(p=0.16)$, although the RIGID condition demonstrated a slightly shorter time to peak (102 $\pm 35 \mathrm{~ms}$ ) compared to the time of the next most rigid condition (108 $\pm 27 \mathrm{~ms}$ ). The mean impact velocity of the ankle was $0.549 \pm 0.077 \mathrm{~m} / \mathrm{s}$ across all conditions, while the mean range of motion of the knee during the impact event was $6.7 \pm 5.2^{\circ}$. No statistically significant differences were found in impact velocity or knee range of motion, indicating consistent initial loading inputs and similar knee joint configurations throughout the experiment.

Total limb stiffness estimates ranged from 14.9 to $17.9 \mathrm{kN} / \mathrm{m}$ (Table 3). The total limb stiffness values calculated from all four conditions were comparable, although a significant difference was found between group distributions $(p=0.04)$. However, in looking at the pairwise comparisons, no significant difference was found after the $p$-value was corrected for multiple comparisons.

\section{DISCUSSION}

The hypothesis of this study was that reducing prosthetic stiffness would decrease total limb stiffness and that this reduced overall limb stiffness would influence the force profile during loading. While a significant difference between reduced prosthetic stiffness and reduced total limb stiffness was found, the pairwise differences

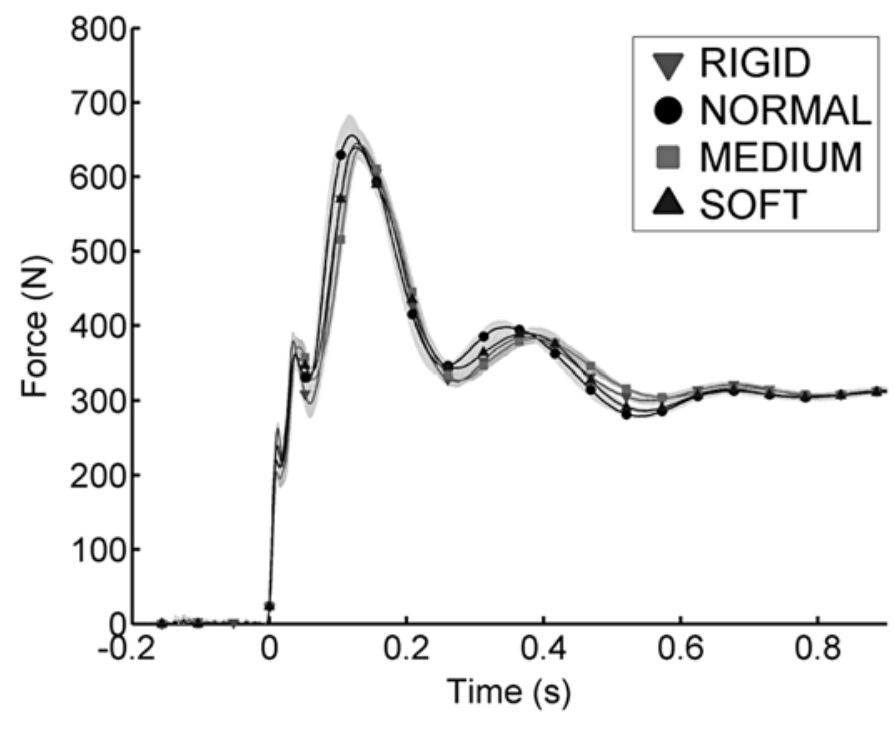

Figure 2.

Force profiles $(n=5)$ for each stiffness condition for a single subject. The shaded regions of the curve correspond to one standard deviation; $t=0$ indicates the start of the impact event.

between conditions were not statistically significant and it was concluded that the study hypotheses were not supported. However, these results are intriguing for a number of reasons. First, peak forces occurring during a controlled impact event remained similar regardless of the prosthetic stiffness. Second, the RIGID condition always represented one of the extreme force or stiffness values (i.e., either the smallest or largest data point compared to other conditions). This result is likely due to the fact that the RIGID condition was 20 to 30 times stifferdepending on spring set-than the NORMAL spring. This trend may indicate that reducing prosthetic stiffness by any amount provides lower shock transmission than a

Table 3.

Mean ( \pm standard deviation) data for all experimental conditions.

\begin{tabular}{|c|c|c|c|c|c|}
\hline $\begin{array}{c}\text { Spring } \\
\text { Condition }\end{array}$ & $\begin{array}{c}\text { Peak Force } \\
(\% \text { BW })\end{array}$ & $\begin{array}{l}\text { Time to Peak } \\
\text { (ms) }\end{array}$ & $\begin{array}{c}\text { Total Limb Stiffness } \\
(\mathrm{kN} / \mathrm{m})\end{array}$ & $\begin{array}{c}\text { Impact Velocity } \\
(\mathrm{m} / \mathrm{s})\end{array}$ & $\begin{array}{c}\text { Knee Range of } \\
\text { Motion }\left({ }^{\circ}\right)\end{array}$ \\
\hline SOFT & $97.5 \pm 13.9$ & $110 \pm 33$ & $15.0 \pm 4.3$ & $0.542 \pm 0.082$ & $6.7 \pm 5.6$ \\
\hline NORMAL & $99.8 \pm 15.2$ & $108 \pm 27$ & $15.5 \pm 4.9$ & $0.542 \pm 0.070$ & $6.4 \pm 4.9$ \\
\hline RIGID & $100.3 \pm 15.0$ & $102 \pm 35$ & $17.9 \pm 10.5$ & $0.562 \pm 0.078$ & $6.9 \pm 5.1$ \\
\hline$p$-Value & 0.04 & 0.16 & 0.04 & 0.12 & 0.58 \\
\hline
\end{tabular}


purely rigid device, but that the amount of the stiffness reduction is inconsequential. It should be noted, however, that the measured reduction in peak force was extremely small and is likely not clinically meaningful. Third, changes in prosthetic stiffness had a smaller than anticipated influence on the total limb stiffness. This result was likely attributable to the physical characteristics of another passive element (e.g., the residual limb soft tissue) within the prosthetic-side limb system.

Lack of change in the characteristics of the impact force peaks and total limb stiffness when prosthetic stiffness was altered suggests that the prosthetic-side limb system was not sufficiently sensitive to the stiffness modifications. The total limb stiffness values reported here are comparable to previous estimates of nondisabled limb stiffness during running, which range from approximately 7 to $18 \mathrm{kN} / \mathrm{m}$ on surfaces of varying compliance [27-29]. The prosthetic-side limb stiffness values calculated for this study are slightly higher than these nondisabled running estimates, which may be the direct result of reduced knee flexion during the impact events compared to running. However, limb configuration alone fails to sufficiently explain the lack of responsiveness of total limb stiffness to the changes in prosthetic stiffness.

Peak impact forces result from the passive change within the system (altered prosthetic stiffness) and the actively modulated compensatory strategy of the limb system. The human neural system is highly adaptable, and the lack of significant difference in the force results may be a result of successful neuromuscular modulation of the loading response during impact. However, the simple, repeatable experimental impact was selected specifically to reduce the involvement of the neuromuscular system. Further, it is unknown whether persons with transtibial amputation are capable of displaying the same ready adaptation to surface (or prosthetic stiffness) that has been demonstrated in nondisabled individuals [30].

Another plausible explanation for the unchanged peak forces relates to the interface between the residual limb and prosthetic socket. Previous studies have suggested that the heterogeneous amount of soft tissue at the limb-socket interface may play a substantial role in total prosthetic-side limb stiffness [31-33]. Large variability within total limb stiffness estimates (ranging from 29\%$59 \%$ of the calculated limb stiffness values) is likely due to the heterogeneity of the residual limb anatomy and characteristics of the limb-socket interface. Because neither the suspension system nor socket was standardized, the suspension mechanisms varied (sleeve, pin lock, etc.) and socket types differed (patellar tendon bearing, total surface bearing, etc.). Additionally, all subjects wore liners within their current prosthetic socket; 13 subjects were fit with an elastomeric liner, while 1 subject used a Pelite liner. Liner materials are often designed to be similar in durometer to human skin, which is far less stiff than any other prosthetic component. The combination of residual limb soft tissue, suspension mechanism, and socket liner may dominate the overall system response during an impact force event, thereby preventing a SAP from influencing total limb stiffness.

\section{Limitations}

Because this study considered a series of elastic elements and characterization of their stiffness, an important limiting factor to consider is the stiffness of the SLED itself. A previous study using a similar force platform indicated a stiffness value of approximately $35,000 \mathrm{kN} / \mathrm{m}$ [30]. However, the custom-fabricated, inclined mounting bracket of the SLED may have introduced additional system compliance. To determine the effect of the mounting bracket, markers were placed on the force platform as a rigidly mounted dummy load of $68 \mathrm{~kg}$ was dropped from the test height of $5 \mathrm{~cm}$. The maximum displacement of any force platform marker in any direction was $<2 \mathrm{~mm}$, and the force platform stiffness was estimated to be 1,000 to $1,500 \mathrm{kN} / \mathrm{m}$. Additionally, the natural frequency of the force platform was determined by striking the platform with a rigid metal object while acquiring force data. The subsequent power spectrum analysis provided an in situ natural frequency estimate of approximately $360 \mathrm{~Hz}$. As both the stiffness and natural frequency of the force platform were at least 10 times that of any experimental conditions or resultant frequencies, it was determined that the setup was adequate for this study.

The SLED experimental protocol specified an extended limb posture during data collection, achieved through hook-and-loop straps and verbal instructions to the subjects. However, all subjects exhibited some knee flexion, with an average range of motion of $6.7 \pm 5.2^{\circ}$. This magnitude represents approximately 50 percent of the knee flexion that has been observed during the stance phase of gait in subjects with transtibial amputations [32]. Also, while knee flexion influences calculation of total system stiffness [34-37], subjects used a similar amount of knee flexion across stiffness conditions. Therefore, knee flexion is unlikely to have substantially 
influenced the limb stiffness calculations or differences between conditions.

While joint position was both controlled and verified through marker data, the degree to which the neuromuscular system may have influenced the results is unknown. A prior nondisabled human pendulum study determined changes in preimpact muscular activations that were attributed to altered motor control strategies [38]. However, some of the altered muscle activations were recorded from muscles that would function differently in individuals with lower-limb amputations (i.e, the tibialis anterior and gastrocnemius), and the extent to which amputation may affect such feedforward strategies is unknown. While future work utilizing electromyography may provide insight into how neuromuscular control might change as prosthetic stiffness is altered, an assumption of the current study was that subjects were not substantially changing their neuromuscular patterns within the course of the experiment.

\section{Future Work}

This study involved a systematic variation in prosthetic stiffness while applying a consistent, investigatorcontrolled impact event beneath the prosthetic limb. However, it has been implied that limb impedance may be adjusted to accommodate both viscous and elastic interface changes [39]. Further investigation into the interaction of all the factors influencing impedance (mass, damping, stiffness) within the prosthetic system could provide valuable insight into the in vivo effect of prosthetic components on limb-loading behaviors. Additionally, reduced-stiffness components have been shown to reduce isolated force transients during fast walking [11], and future studies may benefit from a systematic evaluation of their performance during higher impact activities such as running, stepping down, etc. Finally, the prosthetic-side limb is a complicated system, and each of its elements may influence system behavior in a different way, at a different time, or in combination with one or more other elements. While the individual mechanical characteristics of some prosthetic components (e.g., feet) have been previously reported from benchtop tests, the question of how to isolate the in vivo effects of various elements within the prosthetic-side limb system requires further consideration and may have significant repercussions for prosthetic component design and prescription.

\section{CONCLUSIONS}

The ability of prosthetic stiffness to influence total limb stiffness and affect force profiles during a passive, in vivo impact event was assessed using a novel testing apparatus. Despite a systematic variation in prosthetic stiffness values, no statistically significant differences in peak force magnitude or timing were found between any stiffness conditions. Additionally, a trend of increasing total limb stiffness with increasing prosthetic stiffness was not observed, nor was a significant difference found between conditions. Thus, it appears that reasonable levels of longitudinal prosthetic stiffness provided by means of a SAP may not have a clinically meaningful effect on total limb stiffness. It is theorized that the stiffness and damping properties of another element within the systempossibly the residual limb-prosthetic socket interfacemay be dominating the stiffness changes implemented at the level of the pylon.

\section{ACKNOWLEDGMENTS}

\section{Author Contributions:}

Study concept and design: E. Boutwell, S. Gard.

Acquisition of data: E. Boutwell, R. Stine.

Analysis and interpretation of data: E. Boutwell, R. Stine, S. Gard.

Drafting of manuscript: E. Boutwell.

Critical revision of manuscript for important intellectual content:

E. Boutwell, R. Stine, S. Gard.

Statistical analysis: E. Boutwell.

Obtained funding: E. Boutwell, S. Gard.

Study supervision: S. Gard.

Financial Disclosures: The authors have declared that no competing interests exist.

Funding/Support: This research was funded in part by the National Institute on Disability and Rehabilitation Research of the U.S. Department of Education (grant H133E080009, principal investigators: Steven Gard and Stefania Fatone). This material was based on work supported in part by the Department of Veterans Affairs, Veterans Health Administration, Office of Research and Development, Rehabilitation Research and Development Service (award RX001363). Support was also provided by the Orthotic and Prosthetic Education and Research Foundation (grant OPERF-2013-FA-1).

Additional Contributions: Data for this project were acquired in the JBVAMC Motion Analysis Research Laboratory. The authors would like to acknowledge the prosthetists who donated their time and expertise to this study: Nydia Marzan-Harding, John Michael, and John Brinkmann. The authors would also like to acknowledge AMTI for their generous loan of a force plate and assistance in fabricating a custom mounting bracket for the SLED. Finally, the authors would like to thank Mr. Edward Grahn and Mr. Dilip Thaker for their help in designing and building the SLED. 
Institutional Review: This study was approved by the Northwestern University Institutional Review Board. Written informed consent was obtained from each subject prior to participation.

Participant Follow-Up: The authors do not plan to inform participants of the publication of this study. However, participants have been encouraged to check our Web site for updated publications.

Disclaimer: The opinions contained in this publication are those of the grantee and do not necessarily reflect those of the Department of Education.

\section{REFERENCES}

1. Brughelli M, Cronin J. A review of research on the mechanical stiffness in running and jumping: Methodology and implications. Scand J Med Sci Sports. 2008;18(4):417-26. [PMID:18282225] http://dx.doi.org/10.1111/j.1600-0838.2008.00769.x

2. Kim W, João F, Tan J, Mota P, Vleck V, Aguiar L, Veloso A. The natural shock absorption of the leg spring. J Biomech. 2013;46(1):129-36. [PMID:23200257] http://dx.doi.org/10.1016/j.jbiomech.2012.10.041

3. Lehmann JF, Price R, Boswell-Bessette S, Dralle A, Questad K. Comprehensive analysis of dynamic elastic response feet: Seattle Ankle/Lite Foot versus SACH foot. Arch Phys Med Rehabil. 1993;74(8):853-61. [PMID:8347071] http://dx.doi.org/10.1016/0003-9993(93)90013-Z

4. Lehmann JF, Price R, Boswell-Bessette S, Dralle A, Questad K, deLateur BJ. Comprehensive analysis of energy storing prosthetic feet: Flex Foot and Seattle Foot versus standard SACH foot. Arch Phys Med Rehabil. 1993; 74(11):1225-31. [PMID:8239969]

5. Graham LE, Datta D, Heller B, Howitt J, Pros D. A comparative study of conventional and energy-storing prosthetic feet in high-functioning transfemoral amputees. Arch Phys Med Rehabil. 2007;88(6):801-6. [PMID:17532907] http://dx.doi.org/10.1016/j.apmr.2007.02.028

6. Wagner J, Sienko S, Supan T, Barth D. Motion analysis of SACH vs Flex-foot in moderately active below-knee amputees. Clin Prosthet Orthot. 1987;11(1):55-62.

7. Perry J, Shanfield S. Efficiency of dynamic elastic response prosthetic feet. J Rehabil Res Dev. 1993;30(1):137-43. [PMID:8263824]

8. Strike SC, Wickett O, Schoeman M, Diss CE. Mechanisms to absorb load in amputee running. Prosthet Orthot Int. 2012;36(3):318-23. [PMID:22918909] http://dx.doi.org/10.1177/0309364612450577

9. Lass R, Kickinger W, Guglia P, Kubista B, Kastner J, Windhager R, Holzer G. The effect of a flexible pylon system on functional mobility of transtibial amputees. A prospective randomized study. Eur J Phys Rehabil Med. 2013;49(6):837-47. [PMID:23860421]
10. Berge JS, Czerniecki JM, Klute GK. Efficacy of shockabsorbing versus rigid pylons for impact reduction in transtibial amputees based on laboratory, field, and outcome metrics. J Rehabil Res Dev. 2005;42(6):795-808.

[PMID:16680617] http://dx.doi.org/10.1682/JRRD.2005.02.0034

11. Gard SA, Konz RJ. The effect of a shock-absorbing pylon on the gait of persons with unilateral transtibial amputation. J Rehabil Res Dev. 2003;40(2):109-24.

[PMID:15077637] http://dx.doi.org/10.1682/JRRD.2003.03.0109

12. Berge JS, Klute GK, Czerniecki JM. Mechanical properties of shock-absorbing pylons used in transtibial prostheses. J Biomech Eng. 2004;126(1):120-22. [PMID:15171138] http://dx.doi.org/10.1115/1.1645865

13. van Jaarsveld HW, Grootenboer HJ, de Vries J, Koopman HF. Stiffness and hysteresis properties of some prosthetic feet. Prosthet Orthot Int. 1990;14(3):117-24. [PMID:2095529]

14. Postema K, Hermens HJ, de Vries J, Koopman HF, Eisma WH. Energy storage and release of prosthetic feet. Part 1: Biomechanical analysis related to user benefits. Prosthet Orthot Int. 1997;21(1):17-27. [PMID:9141122]

15. Barr AE, Siegel KL, Danoff JV, McGarvey CL 3rd, Tomasko A, Sable I, Stanhope SJ. Biomechanical comparison of the energy-storing capabilities of SACH and Carbon Copy II prosthetic feet during the stance phase of gait in a person with below-knee amputation. Phys Ther. 1992; 72(5): 344-54. [PMID:1631203]

16. Zelik KE, Collins SH, Adamczyk PG, Segal AD, Klute GK, Morgenroth DC, Hahn ME, Orendurff MS, Czerniecki JM, Kuo AD. Systematic variation of prosthetic foot spring affects center-of-mass mechanics and metabolic cost during walking. IEEE Trans Neural Syst Rehabil Eng. 2011; 19(4):411-19. [PMID:21708509] http://dx.doi.org/10.1109/TNSRE.2011.2159018

17. Lafortune MA, Lake MJ. Human pendulum approach to simulate and quantify locomotor impact loading. J Biomech. 1995;28(9):1111-14. [PMID:7559680] http://dx.doi.org/10.1016/0021-9290(95)00002-Y

18. Bobbert MF, Yeadon MR, Nigg BM. Mechanical analysis of the landing phase in heel-toe running. J Biomech. 1992; 25(3):223-34. [PMID:1564058] http://dx.doi.org/10.1016/0021-9290(92)90022-S

19. Coleman KL, Boone DA, Smith DG, Czerniecki JM. Effect of trans-tibial prosthesis pylon flexibility on ground reaction forces during gait. Prosthet Orthot Int. 2001;25(3): 195-201. [PMID:11860093] http://dx.doi.org/10.1080/03093640108726602

20. Farley CT, Houdijk HH, Van Strien C, Louie M. Mechanism of leg stiffness adjustment for hopping on surfaces of 
different stiffnesses. J Appl Physiol. 1998;85(3):1044-55. [PMID:9729582]

21. Boutwell E, Stine R, Gard S. A novel in vivo impact device for evaluation of sudden limb loading response. Med Eng Phys. 2015;37(1):151-55. [PMID:25465285] http://dx.doi.org/10.1016/j.medengphy.2014.10.008

22. DeVita P, Hortobagyi T. Age increases the skeletal versus muscular component of lower extremity stiffness during stepping down. J Gerontol A Biol Sci Med Sci. 2000;55(12): B593-600. [PMID:11129389] http://dx.doi.org/10.1093/gerona/55.12.B593

23. Aerts P, De Clercq D. Deformation characteristics of the heel region of the shod foot during a simulated heel strike: The effect of varying midsole hardness. J Sports Sci. 1993; 11(5):449-61. [PMID:8301705] http://dx.doi.org/10.1080/02640419308730011

24. Liebermann DG. Biomechanical aspects of motor control in human landing. In: Hong Y, Bartlett R, editors. The Routledge handbook of biomechanics and human movement science. New York (NY): Routledge; 2008. p. 117-28.

25. Greenwood R, Hopkins A. Muscle responses during sudden falls in man. J Physiol. 1976;254(2):507-18. [PMID:1249784] http://dx.doi.org/10.1113/jphysiol.1976.sp011242

26. Cavagna GA. Force platforms as ergometers. J Appl Physiol. 1975;39(1):174-79. [PMID:1150585]

27. Farley CT, González O. Leg stiffness and stride frequency in human running. J Biomech. 1996;29(2):181-86. [PMID:8849811] http://dx.doi.org/10.1016/0021-9290(95)00029-1

28. He JP, Kram R, McMahon TA. Mechanics of running under simulated low gravity. J Appl Physiol. 1991;71(3):863-70. [PMID:1757322]

29. Ferris DP, Louie M, Farley CT. Running in the real world: Adjusting leg stiffness for different surfaces. Proc Biol Sci. 1998;265(1400):989-94. [PMID:9675909] http://dx.doi.org/10.1098/rspb.1998.0388

30. Ferris DP, Farley CT. Interaction of leg stiffness and surfaces stiffness during human hopping. J Appl Physiol. 1997;82(1):15-22, discussion 13-14. [PMID:9029193]

31. Hafner BJ. Transtibial amputee gait adaptation: Correlating residual limb compliance to energy storage and return prosthetic foot compliance in bouncing gait [dissertation]. [Seattle, WA]: University of Washington; 2003.

32. Boutwell E, Stine R, Hansen A, Tucker K, Gard S. Effect of prosthetic gel liner thickness on gait biomechanics and pressure distribution within the transtibial socket. J Rehabil Res Dev. 2012;49(2):227-40. [PMID:22773525]

http://dx.doi.org/10.1682/JRRD.2010.06.0121

33. Koehler SR. An investigation of shock-absorbing prosthetic components for persons with transfemoral amputations [master's thesis]. [Evanston, IL]: Northwestern University; 2005.

34. Greene PR, McMahon TA. Reflex stiffness of man's antigravity muscles during kneebends while carrying extra weights. J Biomech. 1979;12(12):881-91. [PMID:528546] http://dx.doi.org/10.1016/0021-9290(79)90056-3

35. McMahon TA, Valiant G, Frederick EC. Groucho running. J Appl Physiol. 1987;62(6):2326-37. [PMID:3610929]

36. Lafortune MA, Hennig EM, Lake MJ. Dominant role of interface over knee angle for cushioning impact loading and regulating initial leg stiffness. J Biomech. 1996;29(12): 1523-29. [PMID:8945650]

http://dx.doi.org/10.1016/S0021-9290(96)80003-0

37. Lafortune MA, Lake MJ, Hennig EM. Differential shock transmission response of the human body to impact severity and lower limb posture. J Biomech. 1996;29(12):1531-37. [PMID:8945651] http://dx.doi.org/10.1016/S0021-9290(96)80004-2

38. Wakeling JM, Von Tscharner V, Nigg BM, Stergiou P. Muscle activity in the leg is tuned in response to ground reaction forces. J Appl Physiol. 2001;91(3):1307-17. [PMID:11509530]

39. Patritti B. Running shoe cushioning impacts foot-ground interface. Biomechanics. 2004;May:57-67.

Submitted for publication October 14, 2014. Accepted in revised form May 15, 2015.

This article and any supplementary material should be cited as follows:

Boutwell E, Stine R, Gard S. Impact testing of the residual limb: System response to changes in prosthetic stiffness. J Rehabil Res Dev. 2016;53(3):369-78.

http://dx.doi.org/10.1682/JRRD.2014.10.0234

ORCID: Erin Boutwell, PhD: 0000-0002-3682-0073

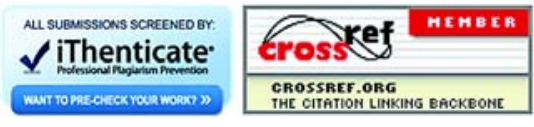

